\title{
Editorial
}

\author{
Fabian Jintae Froese ${ }^{1}$
}

Published online: 15 January 2018

(C) Macmillan Publishers Ltd., part of Springer Nature 2018

Asian Business \& Management (ABM) has been firmly established as a premier outlet for research on general management and business related to Asia. Professor Harukiyo Hasegawa founded and established the journal, with the first issue being published in 2002. Thanks to his great efforts, $A B M$ has been the first journal on Asian business listed in the Social Science Citation Index in 2007. The 2016 impact factor is 1.133 and expected to rise further during the next few years. The second editor-in-chief, Professor Michael A. Witt, along with his editorial team has done an excellent job in working with authors to set high-quality standards. I am thankful for his great support, which facilitated a smooth transition. It is my great honor to succeed Professor Michael A. Witt as Editor-in-Chief of $A B M$ from January 2018. Building on the successful work of my two predecessors, my vision is to further position $A B M$ as a highly reputed journal within the academic community, where researchers would like to publish Asia-related management and business research. While quality and rigorous methodology remain important, $A B M$ will emphasize impact during my editorship. $A B M$ seeks to publish articles that other people would like to read and cite.

The editorial team plays a central role in helping further raise the standing of $A B M$. I am very fortunate to work together with a team of associate editors who are leading experts in different topics, methods, and countries, including Asli Colpan, Kyoto University, Fang Lee Cooke, Monash University, Peter Dowling, LaTrobe University, Axele Giroud, University of Manchester, Martin Hemmert, Korea University, Yipeng Liu, University of Newcastle, Elizabeth Rose, University of Leeds, Tomoki Sekiguchi, Kyoto University, Dylan Sutherland, Durham University, Arup Varma, Loyola University, and Jie Wu, University of Macau. I am also grateful to Katharina Bader, University of Goettingen, who assumes the important

Fabian Jintae Froese

ffroese@uni-goettingen.de

1 University of Goettingen, Platz der Goettinger Sieben 5, 37073 Goettingen, Germany 
role of reviewing editor. Finally, the editorial board and pool of reviewers play an integral part in maintaining the quality of publications.

\section{The scope of ABM}

The scope of articles $A B M$ seeks to publish remains largely the same. $A B M$ encourages submissions on general management and business related to Asia. This would include topics in the areas of corporate governance, human resource management, marketing, organizational behavior, organization theory, strategy, and technology management. Accounting, economics, finance, information systems, and operations research submissions would be unsuitable for $A B M$, unless they have adapted their writing style and deal with a topic relevant for $A B M$. For instance, $A B M$ regularly publishes articles on corporate governance from a finance perspective, though tailored to the $A B M$ audience.

$A B M$ distinguishes itself from general business and management journals as it focuses on the Asian context. By Asian context, we refer to Asian countries, e.g., Swedish R\&D units in China, India, and other Asian countries (Ivarsson and Alvstam 2017), Asian organizations, e.g., human resource management of Japanese companies (Sekiguchi et al. 2016) and individuals, e.g., Korean job seekers (Hong and Kim 2017). Cross-border studies, comparative studies, and single country studies would all be within the scope of $A B M$. Cross-border and comparative studies may also include other non-Asian country contexts as long as the Asian context plays an important role. For instance, there is currently a growing interest in better understanding the internationalization of Asian multinational enterprises in America, Europe, and Africa. More comparative research is encouraged.

The focus on Asia is an important and appealing feature of $A B M$, and authors are advised to emphasize the Asian context. Articles in $A B M$ can highlight the Asian context in three ways. First, indigenous Asian research develops original theories and concepts from Asia. By drawing on Asian thought, indigenous research can contribute to global management scholarship (Meyer 2006). Second, articles can extend established theories by deliberately considering the Asian context in theory building. For instance, studies can replicate an existing Western theory in an Asian country and add further hypotheses that are informed by the unique features of the Asian context. Third, studies can provide insightful contextual descriptions. For instance, articles can provide rich descriptions of the unique Asian context in the introduction, literature review section, methods, and/or discussion section.

In terms of research methods, $A B M$ is open to different methodological approaches. In the past, the majority of articles published in $A B M$ adopted quantitative methods, e.g., survey data, panel data. $A B M$ will continue to publish such articles. In addition, $A B M$ seeks to publish more articles employing qualitative methods as well as conceptual papers, including review articles. $A B M$ also welcomes new, innovative research methods. If so, it would be good if authors explained their innovative methods well. No matter which method, rigorous application of the methods is essential. 
In this editorial, I have outlined the scope of articles $A B M$ seeks to publish. In short, $A B M$ welcomes your submissions on general management and business with a focus on an Asian context open to different methodological approaches. I hope you will continue to support $A B M$ by reading, recommending, reviewing, citing, and writing for $A B M$. I look forward to working for and with you.

\section{References}

Hong, G., and E. Kim. 2017. Overcoming country-of-origin image constraints on hiring: the moderating role of CSR. Asian Business \& Management 16 (4-5): 253-271.

Ivarsson, I., and C.G. Alvstam. 2017. New technology development by Swedish MNEs in emerging markets: the role of co-location of R\&D and production. Asian Business \& Management 16 (1-2): 92-116.

Meyer, K. 2006. Asian management research needs more self-confidence. Asia Pacific Journal of Management 23 (2): 119-137.

Sekiguchi, T., F.J. Froese, and C. Iguchi. 2016. International human resource management of Japanese multinational corporations: Challenges and future directions. Asian Business \& Management 15 (2): 110-136. 